Article

\title{
An Evaluation Framework on Additive Manufacturing for Hydraulic Systems in Wind Turbines Focused on System Simplification
}

\author{
Gergely Kocsis and George Xydis *(1) \\ Department of Business Development and Technology, Aarhus University, Birk Centerpark 15, \\ 7400 Herning, Denmark; kocger@gmail.com \\ * Correspondence: gxydis@btech.au.dk; Tel.: +45-93508006
}

check for

updates

Citation: Kocsis, G.; Xydis, G. An Evaluation Framework on Additive Manufacturing for Hydraulic

Systems in Wind Turbines Focused on System Simplification. Modelling 2021, 2,327-343. https://doi.org/10.3390/ modelling2020017

Received: 27 April 2021

Accepted: 16 June 2021

Published: 19 June 2021

Publisher's Note: MDPI stays neutral with regard to jurisdictional claims in published maps and institutional affiliations.

Copyright: (c) 2021 by the authors. Licensee MDPI, Basel, Switzerland. This article is an open access article distributed under the terms and conditions of the Creative Commons Attribution (CC BY) license (https:// creativecommons.org/licenses/by/ $4.0 /)$.

\begin{abstract}
The wind energy industry showed rapid growth in the past decade, pushing designs to the physical limits. In the last few years, the exponential growth of the wind turbine sizes capped, and the performance upgrades are reached with optimization processes. The first wave was on major parts, but with time advancing the "cost out" strategies are pushed to minor components. A major problem is service costs and the continuous search for missing spare parts in the market. The main aim of this study is to identify when is the best entry point for the additive manufacturing (AM) technology by the hydraulic manufacturer wind turbine companies. From the commercial application for expensive prototypes, it has evolved to economical home use applications. The newly available machines allow printing parts with competing precision to machining equivalents. The material selections range from plastics to metals with mechanical properties equally good or better. This project aims to provide a comprehensive review of the implementation of AM for hydraulic systems in wind turbines. Application screening was done by desk research and on AM technologies. Scientific research has been found on the topic for benchmarking, viability, and cost models. It has been found that there are still missing data for the mechanical properties of the available materials. The result of the decision-weighted matrix shows that the business could gain a competitive advantage by the AM implementation in terms of resources savings and productivity. Although from the technological and market perspective it is justified to initiate before further action the business should review its organization viability.
\end{abstract}

Keywords: additive manufacturing; wind turbine; hydraulic system

\section{Introduction}

The wind energy industry has shown record growth in the past decade owing to Production Tax Credit [1]. Incentives are providing ignition to develop wind energy projects. However, the tax credits are phased out (2019), but developers could still qualify if they start construction before the end of the period [2]. This means that until now original equipment manufacturer (OEMs) were not placing pressure on the sub-suppliers for cost out initiatives. Orsted (form. known as DONG Energy) is working on an offshore wind project aiming to start the development without incentives. In the future, the focus on cost out operations will reach the minor components as well. New initiatives of the existing wind turbine repowering could also provide extra capacity with a rational investment [3].

Both of the collaborating companies in the scope (LJM and Hydra-Grene) have part of their business in the wind energy industry. A significant part of the revenue comes from here, hence it is favorably important to stay competitive and provide state-of-the-art products. To react to the market demands it is a necessity to keep the quality standards high, lead time shorter, and production cost lower. Utilizing additive manufacturing processes could potentially help to react to these requirements. 
Additive manufacturing (AM) is not a new phenomenon. It has been around for many decades primarily used for prototyping. In the 1980s Ford used stereolithography (SLA) for speeding up their new prototype part designs [4]. The SLA technology utilized plastic that has an achievable melting point. This allowed having special parts within the material strength limits to be produced with a possibility to have a modification in each product. To satisfy the higher material strength requirements, certain composite materials have been experimented as an alternative to utilizing existing 3D-printing technologies. In recent years, however, $\mathrm{AM}$ with metal started to receive more attention, due to the high service costs and the continuous search for missing spare parts in the market that resulted in prolonged service times. The recent development is materials and machinery enabled to experiment with a project, which provides alternatives to the subtractive manufacturing. With AM, it is possible that enclosed features that have been only existing as an error of an enthusiastic practicing engineering student are now a potential detail. AM plays a crucial role today, disrupting the existing supply chain model.

Part consolidation shortly leads to fewer components, thus fewer problems. In a hydraulic system, there are a high number of connections, which is directly proportional to the number of functions and the level of complexity. If a hydraulic component could generate less fluid friction or dissipate heat more efficiently, supporting machinery could be downgraded which would result in economic benefits.

Additive manufacturing provides many new possibilities in the manufacturing field. However, most of the manufacturing companies are having difficulties with deciding to invest in such a technology. It is more than just a financial investment; employees must be trained and the whole organization should be able to adapt to the changes $[5,6]$.

The aim of this work is to explore new possibilities by implementing AM beyond limitations and defining the appropriate time to add AM to the portfolio of wind turbine manufacturers. A thorough technical and market-based evaluation to implement AM technologies is implemented by presenting a decision-making matrix.

\section{Theory Review}

The following section of the work explains the theories used in the article. It is important not to mix AM with rapid prototyping (RP). The terms are not far from each other, but $\mathrm{AM}$ is referred to the process and $\mathrm{RP}$ is the result; a product created from a CAD file [7-10].

The most basic question when a business would like to include new technology in their portfolio is whether it is suitable. There are three core questions to identify if AM should be a part of a company's business model [11].

- Will the company have a competitive advantage by implementing AM?

- Is AM technology feasible?

- Is AM economically feasible?

To use the full potential of the AM process it is important to consider both the advantages and disadvantages. The AM process popularity is on the rise and this resulted in a lot of different knowledge without a specific structure.

\subsection{Advantages}

The AM process simplicity has a benefit, which allows reduced time to enter the market with a new product. The technology advantage grants to have features, which were not possible to produce before with the removal machining processes. Creating parts with higher complexity allow fewer components and better functionality [12]. Furthermore, it also allows better product flexibility during product development. Required features are not tied to specific manufacturing processes $[13,14]$.

As Yang et al. [15] points out that AM took the part consolidation to the next level by achieving part count reduction and simplifying assembly compared to Design for Manufacture and Assembly (DfMA), however, the method is not well developed. With the new part consolidation method proposed in the paper, the part count has been reduced by $60 \%$ and 
the weight by $20 \%$. Furthermore, higher complexity and fewer parts mean possible supply chain simplification [16]. During the AM process, less waste is produced as the material requires no or minimum material removal for surface finish or tolerance adjustment. This gives the possibility to use more expensive material with better material properties while keeping the cost at the same level as conventional machining processes [17].

Durãoa et al. [18] highlighted that moving the manufacturing of the products closer to the final location is allowing possible reduced logistics costs, inventory levels in the whole supply chain. However, distributing the manufacturing also comes with disadvantages, which this paper will discuss further.

\subsection{Disadvantages}

Most of the disadvantages of this technology process are just a challenge for now. New developments and improvements are published nearly every week. The level of standardization and certification is still very limited for both the processes, materials and quality control [19]. This could be a tradeoff if the business is heavily relying on certifications.

Distribution of the digital models and reproduction is far less complicated compared to the conventional manufacturing and assembly. Until now the intellectual properties and designs are not defined how they should be handled. Neely [20] states that the current safety regulations optimized to centralized manufacturing would make it difficult to enforce in the new, AM way of manufacturing. In combination with a 3D scanner, it is possible to scan items and reproduce copies. Patents are only protecting innovation.

Besides the advantages listed above the decentralized manufacturing has some disadvantages. It introduces challenges with information management and quality control across manufacturing locations.

The different AM manufacturing process technologies are still very immature and lack quality control during the process. It has not been enough material produced to date to create a sufficient knowledge hub.

The available materials for AM processes are very limited compared to the conventional "removal" type of manufacturing. These materials are generally going through an energy-intensive production as they must be in either a powder, granulate, or wire, not to forget the size uniformity, hence the significantly higher price. For example, the Ti6Al4V costs around \$20 in sheet form and \$200 in granulated form based on the recent Internet research. The higher price also applies to the machinery. Home use 3D-printing machines can be purchased for home use for under $\$ 500$ already, but they operate with cheap thermoplastics. The industrial range with metal feeding materials starts from $\$ 700 \mathrm{k}$ [5]. The bigger and faster machines can cost 100x more. The defined standards and thermal characteristics which have been refined in the last couple of decades cannot be used here. During the printing process, the bond is made by adding a head in some form. The mechanical and thermal characteristics of these materials are different from the standard.

The CAD and CAM software designed for manufacturing have not incorporated AM functions. The software capabilities are still limited as they are optimized for material removal. For some of AM, the production model should contain a supportive structure. To work with these requirements either a dedicated software should be used which is designed for a specific machine or open-source programs which are developed by enthusiastic 3Dprinting communities. Some of the AM processes require supportive structures. The removal of them required post-processing; the difficulty is based on the used material, they could be either dissolved in a liquid or has to be extracted with machinery. The high surface roughness is due to the property that the process is working layer-by-layer. Refinement is possible with finer layers, but this prolongs the manufacturing time.

\subsection{Methodology}

The methodology to be followed is based on the previously introduced design science research methodology. The created process model (Figure 1) is based on Peffers' [21] and 
Kuechler and Vaishnavi's [22] model. The awareness of the problems is defined by the client/context.

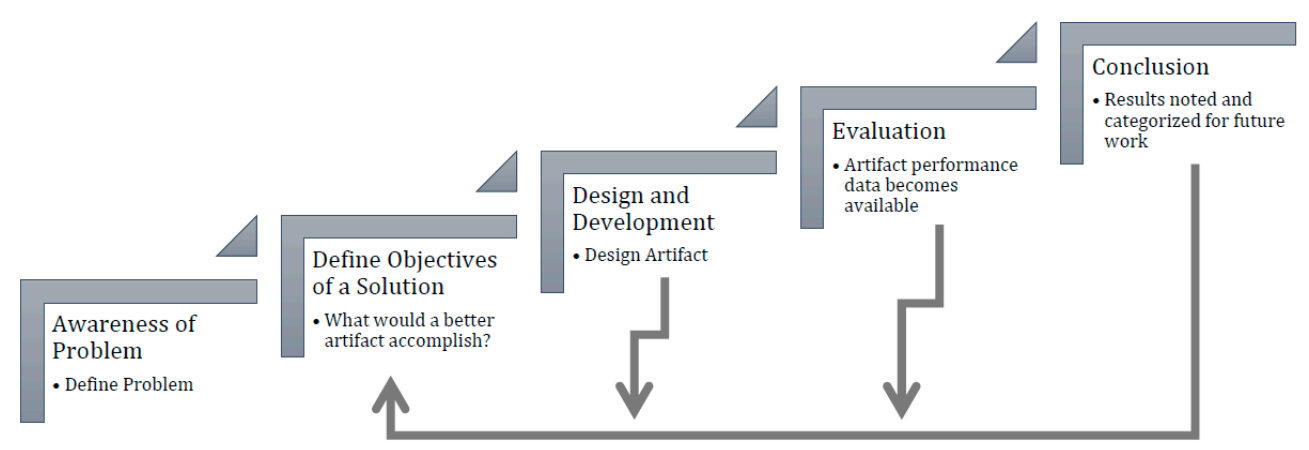

Figure 1. Design science research process model based on [21,22].

In this section the following five activities are explained, and how they have been implemented in the article's structure. As Figure 1 shows these steps are presented in sequential order, however, it is not expected that researchers would follow this form, it should be more considered as a mental model. The steps for the scope of the project are defined as below.

- Activity 1: Awareness of the problem: In the first part of the article, the introduction section identifies the problem, outlines the scope, and states the research motivation.

- Activity 2: Objectives of a solution: The objective of the solution is to find answers to the following questions: What are the possible applications for AM. OEM or after sales? Centralized or decentralized?

- Activity 3: Design and development: The application screening is part of the article where the current AM technology is identified based on desk research and scientific articles. Furthermore, relevant cases are screened and wind turbines with hydraulic machinery are categorized and qualitative data collection by interviews are based on "laddering."

- Activity 4: Evaluation: Combination of quantitative and qualitative evaluation. Qualitative evaluation is done with a weighted decision matrix. The researchers and collaborators observe and measure how well the artifact supports a solution to the problem. The project is summarized in an article and is shared with the collaborators.

- Activity 5: Conclusion: Results noted and categorized for future work.

Research papers were gathered primarily collected by desk research. Quantitative data from Technical documents and scientific publishes. Qualitative data from employees at the collaborating companies via semi-structured interviews and the researcher's knowledge from previous researches. Mix analysis of quantitative and qualitative data.

\subsection{Materials for $A M$}

With the popularity growth of AM technology, a wide size range of applications has been tested for capability. There is a range of available machines allowing 3D print products up to $23 \mathrm{~m}^{3}$, providing 100-micron precision. On the other hand, tolerance is also very much dependent on the used material.

As a disadvantage, there is a limited amount of materials available compared to the conventional processes. Senvol [23] has a list of the currently available materials for the most common processes. A lot of the materials are missing information, such as tensile strength or hardness. To get reliable data only laboratory testing is a viable option. To select the right material, first screening should be done for all material and process requirements and then ranking based on the optimization requirements [24]. There are basic properties, which should be defined according to Kim and Oh [25]: 
- Material compatibility;

- Building volume;

- Support Structures;

- Surface quality;

- Curling/warping;

- Minimal feature sizes;

- $\quad$ Shape Accuracy;

- Resolution and Anisotropy.

When selecting the right process type for AM the engineer should be aware of every process parameters, such as:

- $\quad$ Layer thickness;

- Power setting;

- $\quad$ Speed settings;

- Hatch spacing.

Due to the way of the AM process, in some cases support structures are needed to be designed during the process. Post productions include:

- Support material removal;

- $\quad$ Surface texture modification;

- Precision and aesthetics improvement;

- Property enhancement (non-thermal).

\subsection{Design for Additive Manufacturing (DfAM)}

Before looking into the AM process, it has to be described why we cannot directly apply the existing disciplines. Thompson et al. [26] discusses that design for manufacturing and assembly (DfMA) can be seen from three levels of abstraction. The first level consists of concrete tools and techniques and guidelines on how to adapt a design to constraints. They are specific for the following:

- Process: e.g., Injection Molding design;

- Feature: e.g., part size, weight and symmetry, etc.;

- Activity: e.g., how to calculate the minimum assembly time.

At the second level, DfMA quantifies the effect of the design process and manufacturing on each other.

- Improve performance of the manufacturing system;

- Executing qualities of the product;

- Evolution qualities;

- Long-term potential of the business case.

The top-level explores the design relationship with the manufacturing.

- Material and process selection;

- Concurrent engineering;

- How to improve CAD to support DfMA;

Thompson et al. [26] states that although the definitions mentioned above are valid for AM, in practice all three levels of abstraction are different and requires a new body of knowledge to support DfAM. For e.g., AM can create new features which require different constraints. Each process types must have dedicated design tools and rules. It was also discussed in the paper that it is important to consider from the beginning when working on implementing AM process that has different cost drivers, batch times, and production times from the conventional manufacturing processes.

To incorporate the AM as a manufacturing process the companies must adapt their existing business models. It could either mean creating a new business model or investigating the current business model; what values could potentially AM add [27]. In most cases, if the product is already designed for the specific manufacturing processes chances that the AM could reduce the cost are low. 
Vaneker [28] presents a flowchart (Figure 2) that brings together the AM implementation with the life cycle considerations. It highlighted that the final material and process selection has to be pushed far out as possible. This is in relation to the fact that the designed features do not have to be practical or fitting for a certain type of machinery as milling or turning.

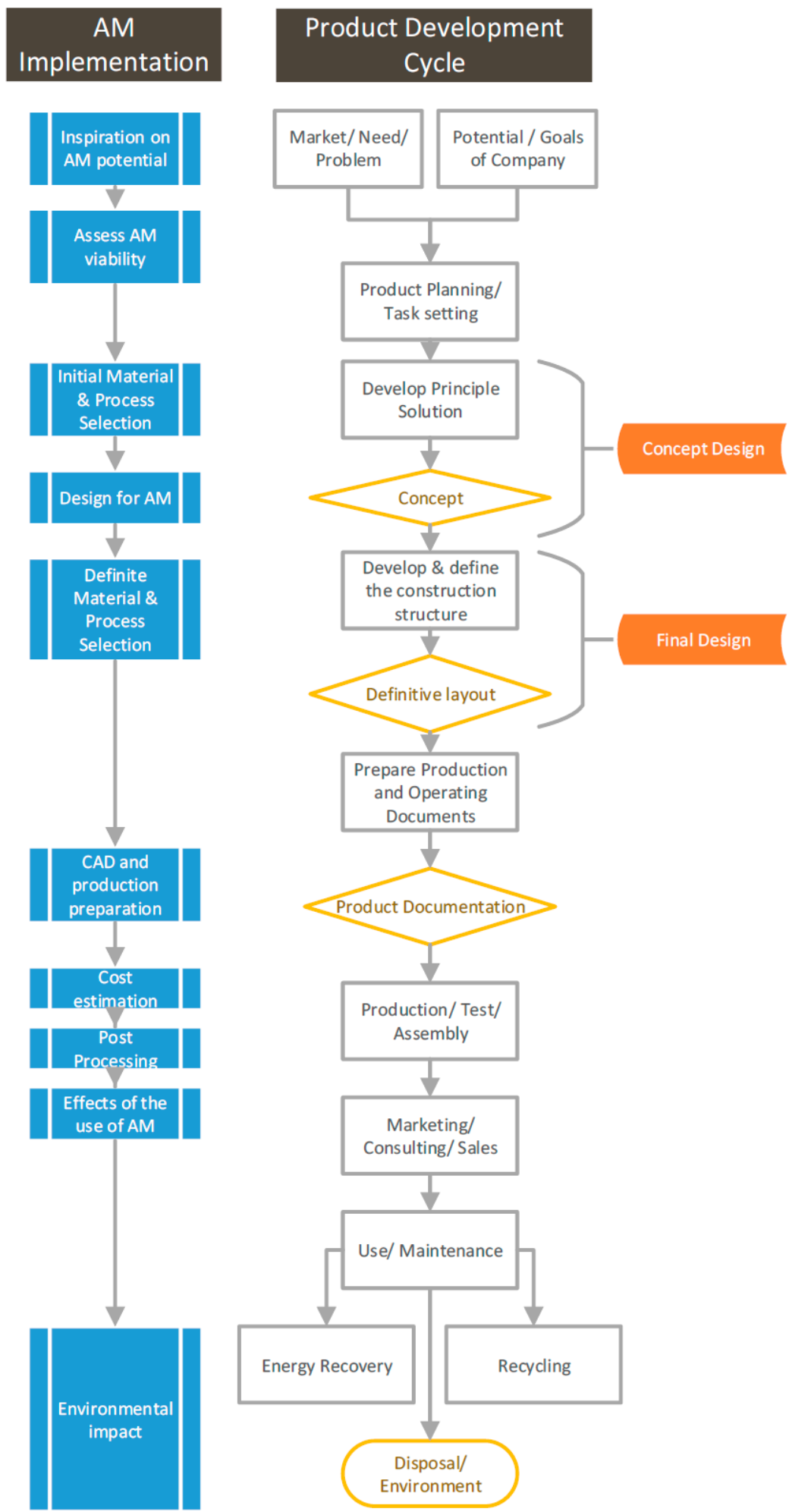

Figure 2. AM-related life cycle considerations are redrawn based on [28]. 
In order to make a qualified decision for the AM viability, a requirement list has to be carefully assembled. To support this line of action, Pahl's [29] requirement list that presents:

- Product planning;

- Definition of basic market demands;

- Attractiveness demand of the market segment;

- Definition of consumer technical requirements;

- Scenario planning and performance requirements update;

- Demands-wishes;

could be utilized as a reference. One of the most beneficial ways to find inspiration for the AM process implementation is to benchmark and research what has been already done. The AM application areas are divided into three levels (Figure 3), each represents the scale complexity [26].

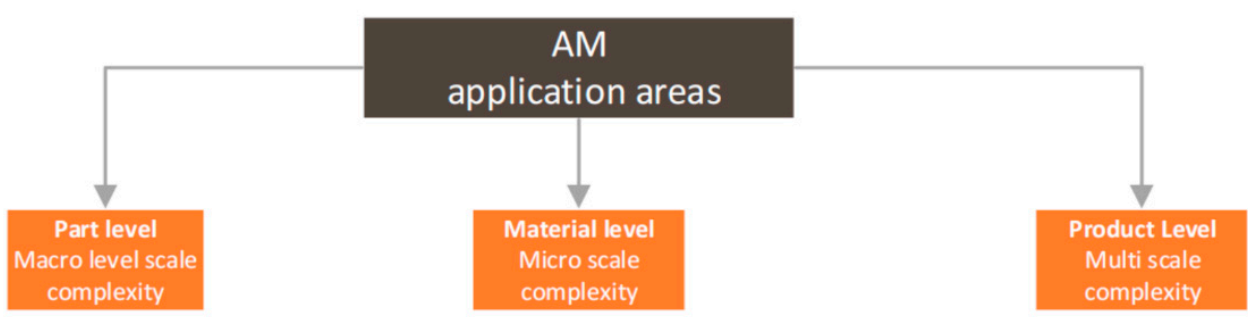

Figure 3. AM application areas, based on [26].

\subsection{Cost of $A M$}

There are many cost models available to date. For e.g., Atzeni and Salmi [30] has worked on a cost comparison between high pressure die casting and selective laser sintering (SLS). The model showed that for up to 42 pieces the SLS is the more economical choice. The most generic models are great to use to compare process costs, however, if the full potential of AM should be utilized the cost and economic benefits should be evaluated by looking at the full life cycle costs.

The machine cost is a significant contributor to the total cost. According to Thompson et al. [26] the electron beam melting (EBM) and direct metal laser sintering (DMLS) are approximately $50 \%$. The materials are also significantly higher in price. The thermoplastics can be 50-120 times higher than used for injection molding. In low production volume the pre- and post-processing labor cost are not negligible; such as a designer and a specialist for the machine operation labor costs. Energy cost is only a minor, $2 \%$ of the total cost.

\section{Wind Industry Market-Hydraulic Systems}

The wind turbine has several thousand components. The industry has been evolving and wind turbines and their components are becoming more complex than ever before [31]. There are ongoing investigations in many areas, which focus on enabling the benefits of 3D-printing technologies. The scope of this article is narrowed down to hydraulic systems. In the wind industry, hydraulic technology has been applied at different levels by turbine manufacturers. There is machinery, which operates without any kind of hydraulics solution and there are others, which utilize the hydraulic systems. The systems available in the market by the collaborator companies are reviewed. In the wind turbine, the hydraulic system is widespread from the tip of the nose cone to the back end of the nacelle. Figure 4 shows the main elements. 


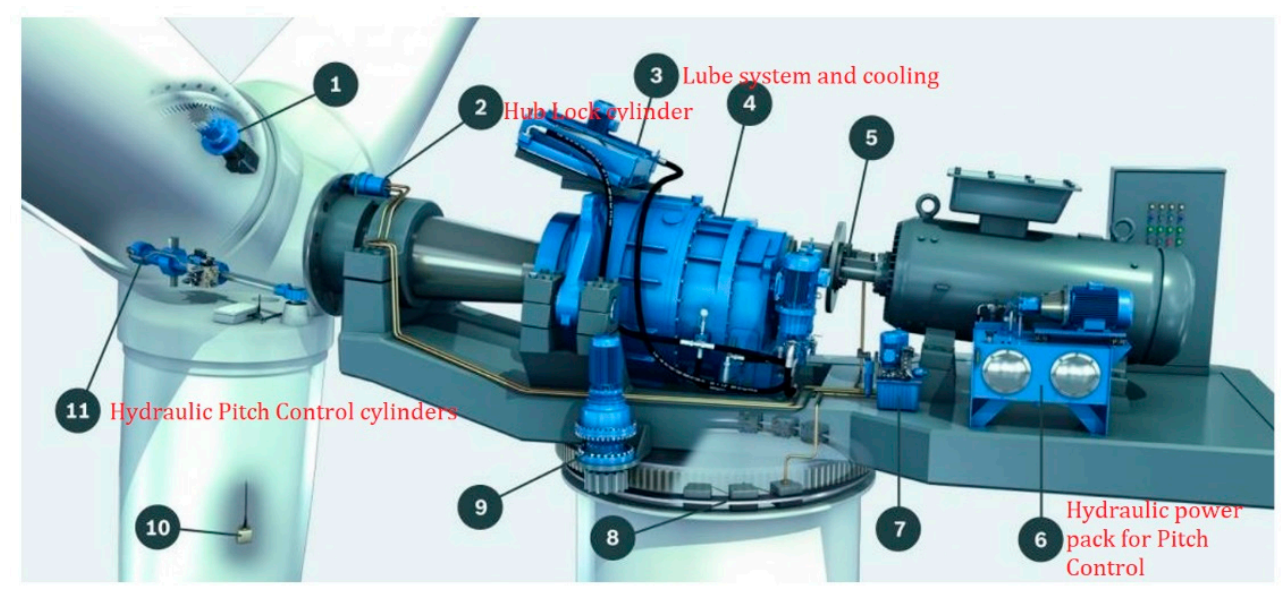

Figure 4. Wind turbine hydraulics [32]; 1-Electromagnetic (rotary) pitch control; 2-hub lock cylinder; 3-lube system and cooling; 4-gearbox; 5-high-speed output shaft; 6-hydraulic power pack for pitch control; 7-brake power back; 8-yaw brake; 9-yaw drive; 10—blade control; 11hydraulic pitch control cylinders.

\subsection{Pitch System}

In the wind turbine, the hydraulic pitch system takes care of the correct alignment with rotor blades.

The first line of the element is the pitch control cylinder (11 on Figure 4). In modern turbines, there are 1 or 2 for each rotor. Each of the cylinders has a manifold block with oil feed and a distribution valve with a control signal. Both the control signal and the hydraulic oil is coming from the nacelle. In order to keep everything in place, these lines are placed thru a slip-ring which allow the connection of the stationary nacelle to the rotary hub. The power-pack (6 in Figure 4) with the motor and the tank is located all at the back of the nacelle. The heat exchanger is also mounted here on the tank.

As the system is widespread, there is a high number of connections, thus the possibility for failure and leakage. In a hydraulic system, it is normal to have $5-10 \%$ leakage of the oil annually (considering the maintenance). Generally speaking, the hydraulic cylinder components are quite heavy (the cylinder is more than $100 \mathrm{~kg}$ and the subcomponents are more than $3 \mathrm{~kg}$ ) with a low level of complications. Most of the system is built from standard hydraulic components, however, the most complex element regarding the oil flow is the manifold blocks. The cylinder is extremely optimized for the current production setup. This is the perfect case where AM could not add an economically feasible value with the complete redesign of the product. On the other hand, the manifold block is a great connection point for multiple components.

\subsection{Cooling and Lubrication System}

The system on the gearbox in the wind turbine should take care of keeping a low viscosity level on the gears and making sure to keep the oil on the desired cleanliness and temperature level ( 3 in Figure 4). The system includes a pump, hoses and tubes, heat exchanger, filter elements, controller unit, and a manifold block, which connects all the hydraulic parts. As the wind turbine is designed to generate electricity is it important that all these supporting systems are energy efficient [33].

According to the Hydra-Grene the secret is in the manifold and the utilization of the filter elements.

\subsection{Hydraulic Structures Viable for AM Process Investigation}

In the following sections, the article will discuss which hydraulic parts are viable for the AM process. The first part will primarily focus on components that are manufactured by the contributor companies and not for the purchased parts. The collaborator companies 
supply both manufactured and bought parts. This article focuses on self-manufactured items only.

In Figure 5, the main AM application areas can be found. The most utilized area is certainly prototyping. Following the re-engineering of the existing products. The creation of new products from scratch is still falling behind as the full potential of the technology could not be reached yet due to the difficulties discussed in the previous sections.

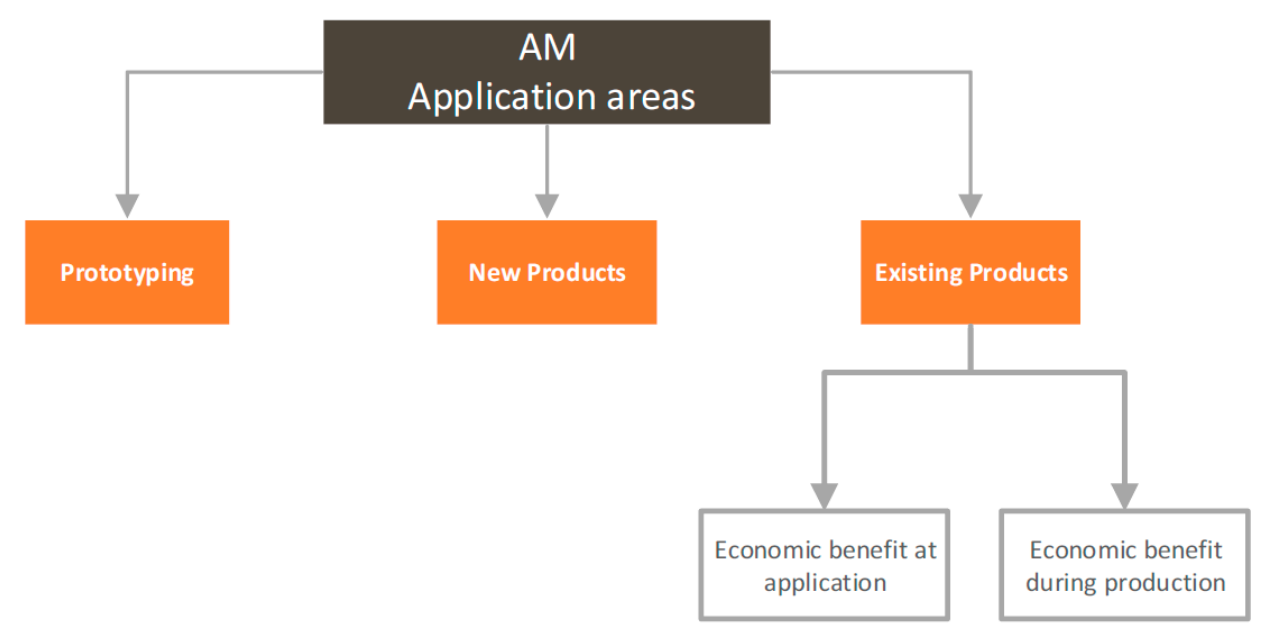

Figure 5. AM application areas, created based on [28].

The products by the contributor companies are the existing products. The application area for AM in this case will be narrowed to exiting products. Since the market requirements are to perform at least 25 years problem-free in the wind turbines both economic benefit scenarios should be considered (Figure 5). Although there are several areas for AM process investigation, both of the collaborating companies incorporate hydraulic manifold blocks either low pressure ( 15 bar) or high pressure (350 bar) systems. Hydra-Grene currently working with a fully automated, robot feeder coupled with a CNC machine.

\section{AM Application Criteria and Screening}

The following section reviews the list of criteria defined by the wind industry (represented by the collaborators). There are three application areas defined in the theory section. This article focuses on the existing products, trying to unlock the economic benefits for the production and the application phases. Based on the authors' experiences in the wind industry and semi constructed interviews with the collaborating companies the following criteria are summarized.

Most of the above-listed criteria (Table 1) correspond to general problems or requirements. In the case of the weights for the criteria, 100 points have been distributed for each of the criteria. The reasons supporting the selection can be seen in the evaluation following the decision-weighed matrix, which is presented below. To ensure validity, the weighing has been separated from the rating. The screening investigated all the application areas evaluating the possibilities based on Thompson et al. [26].

\subsection{Application Areas}

\subsubsection{Part Level-Macro Level Scale Complexity}

In this section, the applications focus on the individual parts. In the wind industry, there is no requirement for aesthetics, but the external freeform geometry focuses on such applications. In this case, it is only a nice-to-have feature, there is no economic justification to support it. 
Table 1. Application criteria.

\begin{tabular}{|c|c|}
\hline Criteria & Note \\
\hline \multicolumn{2}{|l|}{ Pre-Production } \\
\hline Product Redesign & $\begin{array}{l}\text { Designer work needed for modification based on the existing } \\
\text { CAD model }\end{array}$ \\
\hline Initial investment & Cost of the machinery \\
\hline \multicolumn{2}{|l|}{ Production } \\
\hline Material waste & Reduction of machined materials \\
\hline Product weight & $\begin{array}{l}\text { Dry weight Difficult to copy, gives patent possibility of the } \\
\text { assembled product (no oil) }\end{array}$ \\
\hline Alternative material & Using alternative material with similar mechanical properties. \\
\hline Production time & Setup, production and post-processing \\
\hline \multicolumn{2}{|l|}{ Added value } \\
\hline Achieved Complexity & $\begin{array}{l}\text { Higher complexity to allow part consolidation. Move up the } \\
\text { complete assembly in the supply chain; semi-knocked-down } \\
\text { (SKD): partially assembled parts of the product }\end{array}$ \\
\hline Condition monitoring & Possibility to adding condition monitoring feature \\
\hline Maintenance & Improving maintenance possibilities \\
\hline Application performance & Longer lifetime, better performance \\
\hline Uniqueness & Difficult to copy; gives a patent possibility \\
\hline Backward compatibility & Applicable to former wind turbine models. \\
\hline New function & Added feature \\
\hline
\end{tabular}

\subsubsection{Cost-Effective Custom Products}

In general, this application is for ultra-low volume customization, where previously some kind of modularization had to be used in order to stay economical. The need for customized products is very low. In fact, the members of the wind industry are working on defining standards in order to optimize the costs and support quality control.

\subsubsection{Internal Freeform Geometry}

Currently, all the hydraulic systems are restricted to features that are economical to manufacture with conventional material-removing methods. The hydraulic manifold is a great example. The hydraulic oil during operation should flow in perpendicularly aligned channels. Currently the most efficient way to deburr all the internal sharp edges is with the thermal energy method.

AM enables using complex internal structures. The most fluid friction-optimized bends could be utilized because there is no machining preferability. Furthermore, the most widely studied applications are conformal cooling [26].

\subsubsection{Macro-Structure Topology}

Macrostructure topology optimized objects are created by a numerical approach where it is identified whether the material is required in the given location to support the desired functionality [26]. This application could be the most beneficial where weight reduction could result in energy saving over the lifetime of the product. However, weight reduction has not been the primary criteria, using macro structure topology would allow reduced material usage which would allow using alternative/more expensive materials [34].

\subsubsection{Color}

During the manufacturing, some of the AM processes allows having pigment in the feedstock. This feature could allow making features visible and make operation and maintenance processes easier, e.g., hot hydraulic line red, cold blue. However, it is important to note that this is only available with thermoplastics.

\subsubsection{Material Level-Microscale Complexity}

Allows the combination of materials and microstructures. When considering switching to another type of material, certain properties need to be considered, such as plastics may 
not rust, however they may absorb water in such an amount that the changes in the mechanical properties cannot be neglected [35].

\subsubsection{Custom Microstructure and Material Composition}

In the list of the disadvantages for AM, it has been mentioned that there is a challenge with surface roughness. However, the density of the structure can be adjusted for each layer, thus part density and surface roughness can be adjusted as well. Heat treatment could increase the mechanical strength of the metal parts.

\subsubsection{Product Level-Multiscale Complexity}

If there is a complex part such as a landing gear that consists of nine pieces, it is possible to create one single item. AM allows combining existing assembly into and single object. Reducing the number of parts could possibly lead to weight reduction and greater durability.

\subsubsection{Embedded Objects}

Small metal object and electrical components. However, this also only applies to thermoplastics. The manufacturing methods with the metal does not allow to incorporate sensitive electronics unless it has a heat-resistant enclosure.

\subsubsection{Direct Production of Assemblies}

Discontinuous interlinked structures, such as chains. One good example is from the medical industry printing joints, which does not require assembly. On the negative side, the maintainability level of this kind of products is close to zero.

\subsection{Application Areas}

The wind industry supplier market could be separated into two segments. OEM turbine manufacturer or after sales. Essentially the requirements and the timespan are different for each of them. A type of product for the OEM market is normally a long-term product development. The process could be either co-operative between the supplier and $\mathrm{OEM}$; in case the requirements and possibilities are still not defined, or in some cases, there is an already defined technical product specification which the supplier should follow in order to qualify. The time span between the start of the design and the approved product could take months or years. After approval, the product should be manufactured for a longer term (e.g., 2-5 years) before product switch or a progressive change.

On the other hand, the after sales market is looser in regards to the delivered terms. From the lifecycle experience, it can be evaluated if there is an unnecessary feature or part and the weaknesses can be also addressed [36]. After-sales products are commonly placed into systems with several unknowns and variables [37]. To deal with the uncertainty the risk-managing result is to lower the warranty of the product. A typical market routine is to provide 12 months from the start of the operation. To address an existing problem with the product there is a demand for quick and effective solutions, due to the reason that these can have a negative effect on the power output of the turbine resulting in an economical loss. In regard to the previously discussed AM application areas (Figure 5), the current product portfolio would enforce to focus on AM application on existing products.

To unlock all the potentials given by the AM technology the product should be designed from scratch considering the whole system as a greater picture. For e.g., Bosch Rexroth is working on a concept that would utilize hydroelectric systems for pitch control. This would allow minimizing the part count. The idea is still in a prototype phase and AM could potentially help to create more complex parts to improve reliability and costefficiency [38]. 


\subsection{Application Areas-Geographical}

Should this focus on a centralized or decentralized supply chain? Wind turbines can only generate electricity, thus economic benefit when operating. In case of the component failure, either the operation becomes impossible or the monitoring/controlling system switches to the safety mode and the machinery shuts down. To address component failures quickly, the replacement has to be stored close to the operation site. These modern wind turbines are designed to operate for 20-25 years, placed in demanding complex terrains, and there is a new iteration almost every year [39]. In the last 20 years, the hydraulic components became bigger as they had to withstand the rising forces. For e.g., to date, NextEra has more than 38 different models from seven different OEM with a total count of more than 9000 wind turbines. There are different operating strategies to keep the inventory in the supply chain. In some cases, the owners have the most critical components in a warehouse close by and the rest of the parts are at the suppliers' location. It is part of the risk-mitigation strategy to decide which components should be available based on the product cost, historical failure rate, and lead-time.

The wind industry component manufacturing is very centralized. Most of the production reached such a magnitude, which requires the creation of subassemblies, so it complies with transporting capabilities and limitations. For these types of parts, it would not be economical to discuss decentralization. The first step toward better availability and reducing inventory-holding cost, however, is the delivery time and cost [40]. The paper concludes that if a general approach is used for manufacturing, the distribution could be the future, however to date the centralized option is most likely to succeed despite the tradeoffs.

\section{Evaluation and Discussion}

In this section of the article, the previously presented areas are evaluated. In the previous section, three different consideration areas have been screened. Each of these is evaluated separately. The technological application areas are evaluated with a qualitative tool (weighted decision matrix). It compares the qualifications against the criteria set previously. In the matrix, every criterion has a weighted score, which represents the importance. Each application area is compared to a reference, in this case a manifold block manufactured with conventional subtractive technology. Better performance presents positive scores and unfavorable performances, negative scores. The decision matrix is split into part-material-product levels and depending on the stage (pre-production, production, and post-production (added value)), some criteria are evaluated twice or three times as important or not as important ("rate" in the table) as others, based on the experience of the authors. The rates can be both positively or negatively associated. Therefore, depending on the rate and on the weight, which is allocated, the overall score is estimated. In the end, all the scores are summarized. The top three are selected for further action. The market and geographical section have a quantitative, descriptive evaluation. For the numerical assessment, a case scenario should be selected, and detailed calculations should be performed.

Based on the information presented in the theory section and the analysis of the current market, this section of the paper defines the answer to the questions scoped in the problem formulation.

\subsection{Application Evaluation}

In the following decision matrix (Table 2) the application areas have been grouped into two dimensions. Each criterion is separated whether it is focusing on the prior, during the production, and adding sales value to the product. The application methods are kept in the previously presented groups focusing on the structure level. 
Table 2. Decision matrix for application

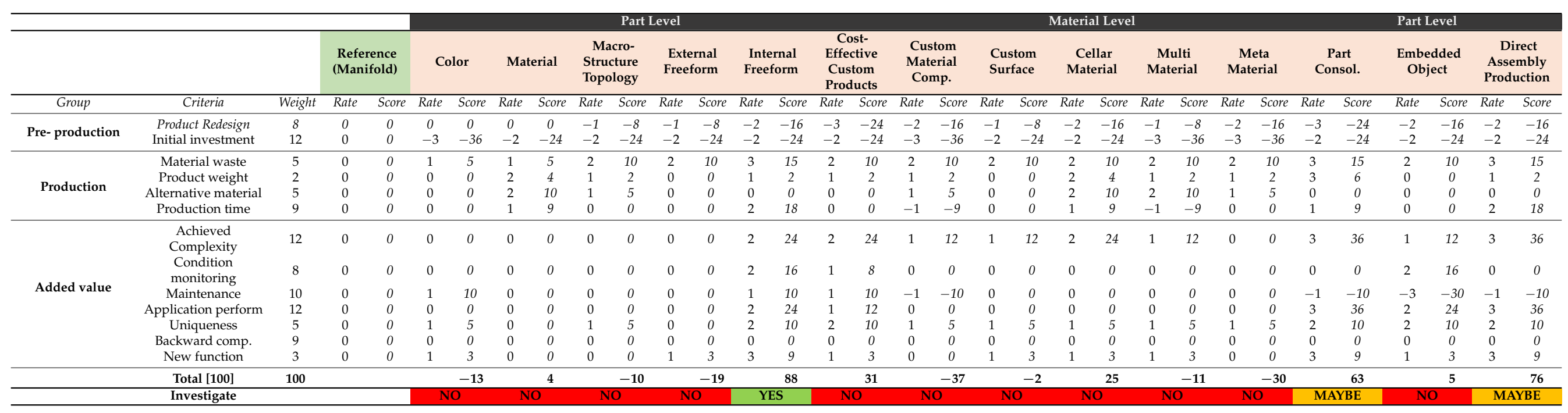


In the following subsections, the criteria are evaluated and reflected in the results presented in Table 2. The reference selected for this matrix was an existing manifold block. The result of the decision matrix shows that the best application approach would be internal freeform. On the second- and the third-place part consolidation and direct assembly are the outcome, due to the high scores in the achieved complexity and the better performance possibility. However, this can be only unleashed if a greater scope is involved and the connected elements are also included in the product redesign.

\subsubsection{Pre-Production}

This group focuses on two criteria which have been outlined. The assumption has made that for every application some kind of machinery is required, thus the negative values in the investment. Based on the knowledge about the machine complexity and requirements there is a variation between -2 and -3 scores. In regards to the product redesign, the hypothesis has been made that the existing CAD model can be used as a point of reference and further redesign work is added in case modification is required to achieve the application. In the part level, the color and material do not need any mentionable modification. However, in order to fully achieve internal freeform, cellar materials and the product level application the design require a greater amount of designer work.

\subsubsection{Production}

The following criteria focus on elements related to the production. Regarding the material waste, all the applications scored higher than the reference as the material for the designed features did not have to be removed. Primarily all the applications received a positive 2 score in the material level selection as all of them improve in optimizing the used material. The weight as a criterion counts only $2 \%$ of the decision. Without looking at the final design it is difficult to estimate what can be achieved with each type of application and weight difference will be almost negligible. The possibility of alternative material allocation grants an extended range of use of materials which leads to a more flexible product portfolio.

The production time purely focuses on the manufacturing processing time. Again, this was very difficult to estimate, so the effect of complexity was considered.

In all three levels, there is one application with the highest score above 30. Internal freeform, cellar material, and direct assembly production.

\subsubsection{Added Value}

Most criteria have fallen under this category. In each of the application, it was evaluated what level of extra complexity can be reached comparing to the reference. This involves both combining existing features and adding new ones. As we are in the era of Industry 4.0 it is crucial to investigate how can we gather information from an operation. Without getting into the details, no specific solution has been selected for the scenario, only the hypothetical possibility has been investigated. Although the maintenance requirement had quite an important weight it had mostly neutral or negative scores. This happened due to a tradeoff of the AM technology. Once it has been made, modifications and repairs are costly or impossible. The only positive score is for the internal freeform and the costeffective custom product. It is important to state that for AM technology, in general, it is possible to design service features, but reassembly is not possible in no-separating components [41]. The improved application performance results in the extra added functionality and part consolidation which allows fewer possibilities for errors.

The uniqueness in the industry is crucial. It was discussed previously in the article that it is easier to reproduce existing products with a 3D scanner, however, internal features are more difficult to copy without a destructive method. The innovation can be still patented and grants development lead before an alteration is developed. The product level and the internal freeform stand out with the scores for this criterion. 
The backward compatibility has received neutral scores along with all the application areas. It is not applications dependent, more like a design decision whether the product will be backwards compatible with previous revisions. The best practice in the DfAM is that keeping the connections as a point of reference and redesigning all the rest from scratch. The possibility is secondary to the selected application and material. The full potential can be explored during the redesign of the product. The probability was scored based on the scoping reference cases.

\subsection{Market Focus Evaluation}

In the case of the two market sectors for the wind industry, both of them are viable for AM. It is beneficial for the OEM market that the products can be designed from scratch and a greater assembly could be involved with the purpose of simplification. In the case of the after-sales market, the re-engineered products have a long list of constraints to comply with, but it is easier to define a narrow achievable scope. After all the materials and machinery for the AM, technology is still in the development phase [42,43].

\subsection{Application Evaluation}

The geographical aspect of the application is less wind industry-specific. For longterm improvement, it is crucial that the developments are performed in a controlled environment [44-46]. There is a great possibility that in the near future an approach will form for the development of general rapid manufacturing focusing on spare part supply with a certain size limit. However, the development of the transportation industry can also lead to such a result with the drone technology that the lead-time and cost would not justify decentralization.

\section{Conclusions}

The main purpose of this article was to find out when and what is the best entry point for AM technology by the collaborating hydraulic manufacturer companies. The scope was narrowed down to market the wind turbines. The theory section of the project showed that there are many benefits and tradeoffs that should be considered when working with $\mathrm{AM}$. There is a solid base for the design for AM by definitions and frameworks created for DfMA but the specific knowledge core has to be rebuilt around the new possibilities. A lot of the applications are based on existing products. The best way for these is still to take the reference points and start from scratch.

To answer Doubrovski's et al. questions [11]; the decision weighed matrix justified that there is definitely a competitive advantage by implementing AM. The AM technology is feasible economically with certain limitations. It is time to add AM to hydraulic manufacturer wind turbines companies' business portfolio. Although this article justifies that from the technical and economic/market point of view it is time to implement AM technologies, the organization capabilities must be also evaluated. Like the reform needed to the DfAM the company structure and quality system will also require adjustments and sacrifices.

Author Contributions: Conceptualization, G.K.; methodology, G.K. and G.X.; validation, G.X. and G.K. investigation, G.K.; data curation, G.K.; writing—original draft preparation, G.K.; writingreview and editing, G.X.; visualization, G.X. and G.K.; supervision, G.X. All authors have read and agreed to the published version of the manuscript.

Funding: This research received no external funding.

Conflicts of Interest: The authors declare no conflict of interest.

\section{References}

1. U.S. Senate Documents. Bennet Welcomes Reports Showing Record Growth in Wind Energy Industry; Federal Information \&News Dispatch, Inc.: Washington, DC, USA, 2013.

2. AWEA. Production Tax Credit. 2017. Available online: https://cleanpower.org/ (accessed on 6 December 2020). 
3. U.S. Energy Information Administration. Repowering Wind Turbines Adds Generating Capacity at Existing Sites. 2017. Available online: https: / / www.eia.gov/todayinenergy/detail.php?id=33632 (accessed on 26 November 2020).

4. Ford Motor Company. Building in the Automotive Sandbox. 2016. Available online: https://corporate.ford.com/innovation/ building-in-the-automotive-sandbox.html (accessed on 26 November 2020).

5. Kocsis, G.; Møller, J.R.; Sørensen, A.K.; Møller, K. Implementation of Additive Manufacturing Technology at Kyocera Unimerco; Dept. of Business Development and Technology: Herning, Denmark, 2017.

6. Kocsis, G.; Xydis, G. Repair Process Analysis for Wind Turbines Equipped with Hydraulic Pitch Mechanism on the U.S. Market in Focus of Cost Optimization. Appl. Sci. 2019, 9, 3230. [CrossRef]

7. Pereira, T.; Kennedy, J.V.; Potgieter, J. A comparison of traditional manufacturing vs additive manufacturing, the best method for the job. Procedia Manuf. 2019, 30, 11-18. [CrossRef]

8. Hällgren, S.; Pejryd, L.; Ekengren, J. (Re)Design for Additive Manufacturing. Procedia CIRP 2016, 50, 246-251. [CrossRef]

9. Dalpadulo, E.; Pini, F.; Leali, F. Integrated CAD platform approach for design for additive manufacturing of high performance automotive components. Int. J. Interact. Des. Manuf. IJIDeM 2020, 14, 899-909. [CrossRef]

10. The Technology House. What Is the Difference between 3D Printing, Additive Manufacturing, and Rapid Prototyping? 2014. Available online: https:/ / www.tth.com/blog/what-is-the-difference-between-3d-printing-additive-manufacturing-and-rapidprototyping (accessed on 2 May 2020).

11. Doubrovski, Z.; Verlinden, J.C.; Geraedts, J.M.P. Optimal Design for Additive Manufacturing: Opportunities and Challenges. In Proceedings of the International Design Engineering Technical Conferences and Computers and Information in Engineering Conference, Washington, DC, USA, 28-31 August 2011; Volume 54860, pp. 635-646.

12. Cotteleer, M.; Joyce, J. 3D opportunity: Additive manufacturing paths to performance, innovation, and growth. Deloitte Rev. 2014, $14,5-19$.

13. Gibson, I.; Rosen, D.; Stucker, B. Additive Manufacturing Technologies: 3D Printing, Rapid Prototyping, and Direct Digital Manufacturing, 2nd ed.; Springer: New York, NY, USA, 2010.

14. Ian Gibson, I.G. Additive Manufacturing Technologies 3D Printing, Rapid Prototyping, and Direct Digital Manufacturing; Springer: New York, NY, USA, 2015.

15. Yang, S.; Tang, Y.; Zhao, Y.F. A new part consolidation method to embrace the design freedom of additive manufacturing. J. Manuf. Process. 2015, 20, 444-449. [CrossRef]

16. Haghighat Khajavi, S.; Flores Ituarte, I.; Jaribion, A.; An, J.; Chee Kai, C.; Holmstrom, J. Impact of Additive Manufacturing on Supply Chain Complexity. In Proceedings of the 53rd Hawaii International Conference on System Sciences, Maui, HI, USA, 7-10 January 2020.

17. Ford, S.; Despeisse, M. Additive manufacturing and sustainability: An exploratory study of the advantages and challenges. J. Clean. Prod. 2016, 137, 1573-1587. [CrossRef]

18. Durao, L.F.C.S.; Christ, A.; Anderl, R.; Schützer, K.; Zancul, E. Distributed Manufacturing of Spare Parts Based on Additive Manufacturing: Use Cases and Technical Aspects. Procedia CIRP 2016, 57, 704-709. [CrossRef]

19. Monzón, M.D.; Ortega, Z.; Martínez, A.; Ortega, F. Standardization in additive manufacturing: Activities carried out by international organizations and projects. Int. J. Adv. Manuf. Technol. 2014, 76, 1111-1121. [CrossRef]

20. Neely, E.L. The Risks of Revolution: Ethical Dilemmas in 3D Printing from a US Perspective. Sci. Eng. Ethic 2015, 22, 1285-1297. [CrossRef]

21. Peffers, K.; Tuunanen, T.; Rothenberger, M.A.; Chatterjee, S. A Design Science Research Methodology for Information Systems Research. J. Manag. Inf. Syst. 2007, 24, 45-77. [CrossRef]

22. Kuechler, W.; Vaishnavi, V. A Framework for Theory Development in Design Science Research: Multiple Perspectives. J. Assoc. Inf. Syst. 2012, 13, 395-423. [CrossRef]

23. Senvol. Material Search. 2017. Available online: http://senvol.com/5_material-search/ (accessed on 2 May 2020).

24. Ashby, M.; Shercliff, H.; Cebon, D. Matériaux: Ingénierie, Science, Procédé et Conception; PPUR Presses Polytechniques: London, UK, 2013.

25. Kim, G.D.; Oh, Y.T. A benchmark study on rapid prototyping processes and machines: Quantitative comparisons of mechanical properties, accuracy, roughness, speed, and material cost. Proc. Inst. Mech. Eng. Part B J. Eng. Manuf. 2008, 222, 201-215. [CrossRef]

26. Thompson, M.K.; Moroni, G.; Vaneker, T.; Fadel, G.; Campbell, R.I.; Gibson, I.; Bernard, A.; Schulz, J.; Graf, P.; Ahuja, B.; et al. Design for Additive Manufacturing: Trends, opportunities, considerations, and constraints. CIRP Ann. 2016, 65, 737-760. [CrossRef]

27. Turner, C.J.; Moreno, M.; Mondini, L.; Salonitis, K.; Charnley, F.; Tiwari, A.; Hutabarat, W. Sustainable production in a Circular Economy: A business model for re-distributed manufacturing. Sustainability 2019, 11, 4291. [CrossRef]

28. Vaneker, T. The Role of Design for Additive Manufacturing in the Successful Economical Introduction of AM. Procedia CIRP 2017, 60, 181-186. [CrossRef]

29. Pahl, G.; Beitz, W.; Feldhusen, J.; Grote, K.H. Product development process. In Engineering Design; Springer: London, UK, 2007; pp. $125-143$.

30. Atzeni, E.; Salmi, A. Economics of additive manufacturing for end-usable metal parts. Int. J. Adv. Manuf. Technol. 2012, 62, 1147-1155. [CrossRef] 
31. Enevoldsen, P.; Xydis, G. Examining the trends of 35 years growth of key wind turbine components. Energy Sustain. Dev. 2019, 50, 18-26. [CrossRef]

32. Wind Energy Network. Bosch Rexroth-Wind Energy Network. 2017. Available online: https://www.boschrexroth.com/en/ xc/industries/machinery-applications-and-engineering/renewable-energies/wind-energy/products-and-solutions/index (accessed on 21 November 2020).

33. Hydra-Grene A/S. Oil Lubrication Systems. 2017. Available online: https://www.hydra.dk/store/hydra-wind/en/content/ hydra-oil-lubrication-en (accessed on 26 November 2020).

34. Meng, L.; Zhang, W.; Quan, D.; Shi, G.; Tang, L.; Hou, Y.; Breitkopf, P.; Zhu, J.; Gao, T. From Topology Optimization Design to Additive Manufacturing: Today's Success and Tomorrow's Roadmap. Arch. Comput. Methods Eng. 2020, 27, 805-830. [CrossRef]

35. Kerns, J. Machine Design. 2016. Available online: http://www.machinedesign.com/materials/replacing-metal-plastic. (accessed on 6 December 2020).

36. Nanaki, E.A.; Xydis, G. Exergetic Aspects of Renewable Energy Systems: Insights to Transportation and Energy Sector for Intelligent Communities; CRC Press: Boca Raton, FL, USA, 2019.

37. Martinez, V.; Radnor, Z.; Cavalieri, S.; Gaiardelli, P.; Ierace, S. Aligning strategic profiles with operational metrics in after-sales service. Int. J. Product. Perform. Manag. 2007.

38. Banks, J. Adding Value in Additive Manufacturing: Researchers in the United Kingdom and Europe Look to 3D Printing for Customization. IEEE Pulse 2013, 4, 22-26. [CrossRef]

39. Xydis, G. A wind energy integration analysis using wind resource assessment as a decision tool for promoting sustainable energy utilization in agriculture. J. Clean. Prod. 2015, 96, 476-485. [CrossRef]

40. Holmström, J.; Partanen, J.; Tuomi, J.; Walter, M. Rapid manufacturing in the spare parts supply chain: Alternative approaches to capacity deployment. J. Manuf. Technol. Manag. 2010, 21, 687-697. [CrossRef]

41. Durakovic, B. Design for additive manufacturing: Benefits, trends and challenges. Period. Eng. Nat. Sci. PEN 2018, 6, 179-191. [CrossRef]

42. Stock, G.N.; McDermott, C.M. Organizational and strategic predictors of manufacturing technology implementation success: An exploratory study. Technovation 2001, 21, 625-636. [CrossRef]

43. Mottonen, M.; Harkonen, J.; Belt, P.; Haapasalo, H.; Similä, J. Managerial view on design for manufacturing. Ind. Manag. Data Syst. 2009, 109, 859-872. [CrossRef]

44. Maidin, S.B. Development of a design feature database to support design for additive manufacturing (DfAM). Assem. Autom. 2012, 32, 235-244. [CrossRef]

45. Bassett, K.; Carriveau, R.; Ting, D. 3D printed wind turbines part 1: Design considerations and rapid manufacture potential. Sustain. Energy Technol. Assess. 2015, 11, 186-193. [CrossRef]

46. Frazier, W.E. Metal Additive Manufacturing: A Review. J. Mater. Eng. Perform. 2014, 23, 1917-1928. [CrossRef] 